\title{
Analysis of a complex shape chain plate using Transmission Photoelasticity
}

\author{
N. Dasari ${ }^{1}$ and K. Ramesh ${ }^{2}$
}

${ }^{1}$ Engineering Design Centre, Tube Investments of India, Avadi, Chennai, India-600054

${ }^{2}$ Dept. of Applied Mechanics, Indian Institute of Technology Madras, Chennai, India-600036

\section{ABSTRACT}

Most chains are an assembly [1] of five parts namely, outer plate, inner plate, bush, pin and roller. Two inner plates are press fitted with two bushes to form an inner block assembly. The outer plates are press fitted with pins after keeping the pins through the assembled bushes of the inner block. Roller is a rotating member and placed over the bush during inner block assembly. Inner block assembly is the load transfer member from sprocket tooth. The outer block assembly helps in holding and also to pull the inner block over the sprocket teeth. If a chain length is in odd number of pitches, it requires an offset plate as shown in Figure 1 to connect two ends of the chain together to make chain endless. When the chain is assembled with an offset plate, the chain fatigue life was observed only 20 to $25 \%$ of the total life of a chain, assembled without an offset plate. The holes in the offset plate are of the same size as in the outer and inner plates respectively and it is a complex in shape chain plate. A inbuilt thinning zone at the centre of the chain plate as shown in Figure 1 is unavoidable.

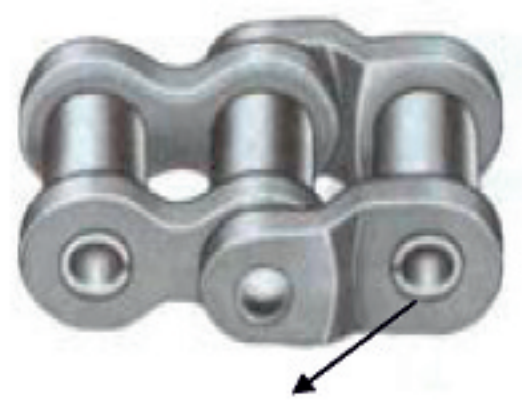

Offset Plate

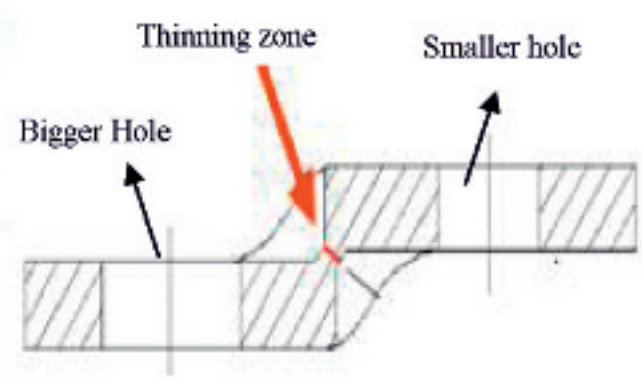

Sectional image of offset plate

Fig.1A complex shape chain plate

The stresses and its distribution in this complex shape chain plate geometry play a critical role in the fatigue life performance of a chain assembly. However, it is difficult identify the stress distribution and stress concentration zones precisely using only the conventional industrial friendly tools such as routine quality control test, breaking load test and numerical computations. In this context the transmission photoelastic technique has made it possible to identify the stress distribution, its concentration and also to quantify the stress and strain [2-3] at any point in the chain plate. This 
paper explains how transmission photoelastic technique is used to estimate the stress distribution and its concentration zones in a complex chain plate when it isloaded.

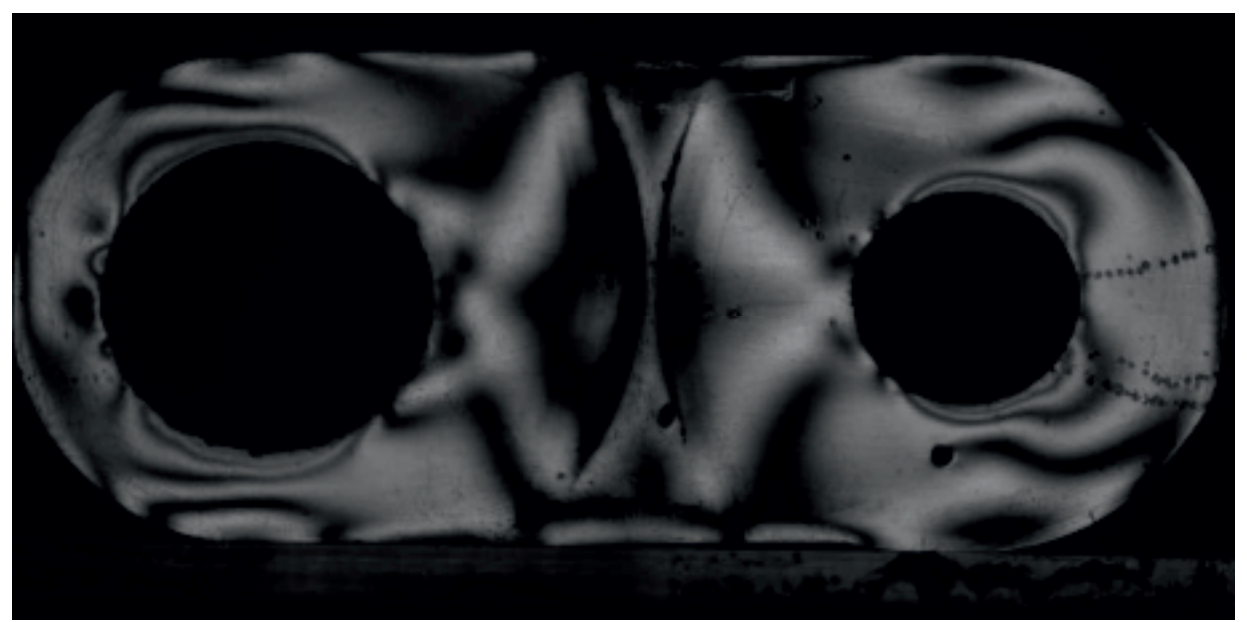

Fig.2Fringes observed in the stress frozen model

An epoxy chain plate model was made through the casting method using a Perspex mould [2-3]. A loading fixture was used to load the model during stress freezing in the furnace. The integrated fringe pattern of the offset chain plate is shown in Figure 2. Slices are cut in the offset zone to understand the nature of the stress distribution. A Simple photoelastic analysis of this has revealed a wealth of information to take suitable decision on the design of such plates taking into account the constraints in manufacturing.

\section{REFERENCES}

1 John, L. Wright., Standard Handbook of Chains, “Chains for Power Transmission and Material Handling" second edition, American chain association, Taylor and Francis, U.S.A, (2006).

2 Ramesh, K., Digital Photoelasticity: Advanced Techniques and Applications, Springer-Verlag, Berlin, Germany, (2000)

3 Ramesh K., e-Book on Experimental Stress Analysis, IIT Madras (2009) URL: http://apm.iitm.ac.in/smlab/kramesh/book_5.htm 